\title{
US Image in the Gulf Press Analytical Study of Al-Khaleej Newspaper of UAE and Al-Sharq Al-Awsat of Saudi Arabia
}

\author{
Aisha Abdullah Al-Nuaimi*
}

Mass Communication Department, College of Humanities and Social Sciences, UAE

\begin{abstract}
The relationship between the Arab world and the US involves many variables and political, economic and cultural problems. This is because such relation is always based on an active and dominating actor namely the United States, and on a state of imbalance of power. Here, the positions of the second party (the Arab World) are linked to some sort of international variables in the American policy towards Arab states. The image of the United States in the Gulf media is governed by four main factors:

First: The relation or link between Gulf political systems and the United States. Second: The nature of the relation between the media and the ruling political system. Third: The stakes lie in the ability of the independent newspapers to provide another (counter) reading to uncover the secrets of the relations between the Gulf media and the American policy. Fourth: To what extent there is a balance in the flow of information between those who have it and those who do not have it; in the absence of the so called knowledge gap.

The study aims at analyzing and interpreting the image of the United States in the print Gulf media. It focuses on Al-Khaleej newspaper of the United Arab Emirates and Al-Sharq Al-Awsat newspaper of Saudi Arabia, published in London. Plus sub other objectives.

The main question of this study is to analyze the image of U.S.A in the Gulf Press? Plus others questions.

In its analysis of the published material, the study used the qualitative discourse analysis. The studies show that print media propagate the policy of the political regime or what it tries to convey to the public opinion. The image of the United States in the Gulf media is the same image the political regimes try to convey to the public opinion.
\end{abstract}

Keywords: Interpretation; Fragile demographic; Political communications

\section{Introduction}

When we describe the relationship between the two sides, we can distinguish between two key parties: The first is the Arab governments or political regimes, while the second is the Arab peoples. If we look at the governments in general, we will find that they all endeavor to win the US satisfaction, especially in light of the changes taking place in the international environment as well as the need of Arab countries to cement their legitimacy and harness their domination of the local public opinion in their society on key issues of direct relevance to the political change or activity.

The second party emerges in the positions of peoples, which are reflected in many political studies and analyses. The Arab peoples look at the United States as a hegemonic power seeking to impose its strategy and political interests without heeding the important issues of the Arab world. This popular rejection of the American policies has increased after the September 11 attacks.

The position of the United States towards the Arab media can be best summarized from US President George Bush interview with a newspaper in which he said, "The Arab media is not fair to us." $\mathrm{He}$ described it as one of unfair and negative propaganda methods, which do not give true impression. He also described it as devilish media. Moreover, a report published by New York Times on 25 May 2008, said that the United States failed to use the strongest weapon in the intellectual war waged against it. This position is also clear in an article by the renowned American journalist Thomas Freedman in which he said, "Arab media nurtured Arabs with feelings of hatred against the United States."
When we speak about media discourse or writings addressed to the Arab public opinion and its relation to the United States, we deal with the ability of this discourse to create any change in the Arab mindset. This is a long-term strategy that aims at building an ethical, political and legal system. That is to say building a model based on the American perspective. This is the objective of the United States on which we should focus when we read the Arab media writings in general and the Gulf discourse in particular in handling the US foreign policy in the Arab region.

We should refer in this respect to the reality of the freedom of the press in the Gulf region. It reflects a special way of controlling the content through the adoption of direct domination through laws and legislations enacted by the government and in an indirect way through the disguised violations of the freedom of the press, whose results are less serious than those in other states. On the contrary, the lack of direct and public clash between Gulf governments and the media in the society makes it a continuous state of affairs and tolerates it. A journalist may come under pressure to ignore many issues through the use of verbal mechanisms and methods that have no legal basis.

*Corresponding author: Aisha Abdullah Al-Nuaimi, Mass Communication Department, College of Humanities and Social Sciences, UAE; E-mail: aisha.noaimi@uaeu.ac.ae

Received August 04, 2012; Accepted September 27, 2012; Published October 04, 2012

Citation: Al-Nuaimi AA (2012) US Image in the Gulf Press Analytical Study of Al-Khaleej Newspaper of UAE and Al-Sharq Al-Awsat of Saudi Arabia. J Mass Commun Journalism 2:124. doi:10.4172/2165-7912.1000124

Copyright: (c) 2012 Al-Nuaimi AA. This is an open-access article distributed under the terms of the Creative Commons Attribution License, which permits unrestricted use, distribution, and reproduction in any medium, provided the original author and source are credited. 


\section{Problem and importance of the study}

The image of the United States in the Gulf media is governed by four main tests:

- First test: The relation or link between Gulf political systems and the United States.

- Second test: The nature of the relation between the media and the ruling political system. This relation is based on the fact that most media and official institutions are part of the political system. Therefore, the public policy of these institutions is in fact a reflection of the policy of the political regime to which it belongs.

- Third test: The stakes lie in the ability of the independent newspapers to provide another (counter) reading to uncover the secrets of the relations between the Gulf media and the American policy.

- Fourth test: To what extent there is a balance in the flow of information between those who have it and those who do not have it. In the absence of the so called knowledge gap, there is shrinkage of the idea of domination, which is always absent when we follow the image of the United States in the official print Gulf media. In Several initiatives of the states of the Gulf region, especially those related to political reforms and educational strategies, the media stressed the issue of the independence of Gulf political regimes in the decision making process. Moreover, we find no mention about the existence of any pressures or the reality that should be accepted. Generally speaking, there is no clear policy to confront the US agenda. Hence the role of the media harnesses subjugation to the one-way American model, which instils the idea of the American domination of the Gulf mindset rather than being an auxiliary factor for rejection and change.

Following this complex relation between Arab political regimes and the United States on the one hand and between the political regimes and the media on the other, this study attempts to analyze the image of the United States in the print Gulf media, while not separating the process of analysis and interpretation from its political and cultural context.

The study basically looks into the big picture. It attempts to see whether the US domination appeared writings, editorials, blogs and analyses in the Gulf press.

\section{Previous studies}

The subject of this study has not been topic of adequate analysis and research based on the fact that it aims at analyzing the US image in Arab media and the press and not vice versa. Earlier studies focused on analyzing the image of Arabs in the US media.

When we examine the scope of the subject of the study, namely "Gulf Media" we find that earlier studies in this respect are very rare if not totally absent. This study takes a research variable from the "press", or from other studies that aims at analyzing the Gulf media literature and writings from a perspective that sees the necessity of not separating the media and its political and economic context.

There are lots of writings that covered the analysis of the relationship between the Arab Gulf states and the United States from two different perspectives:

The first sees that there are several factors that necessitate positive interaction with the American policy for several considerations including the imbalance of power between the states of Gulf and their regional and international surroundings as well as the fragile demographic, human and military environment. Hence, their openness to the American model would help them to enhance their power and enable them to implement their economic and political strategies.

The second perspective says that the reliance of the states of Gulf on the American presence reduces the degree of their independence and ability to take decisions related to their political and economic interests. Moreover, it also leads to increasing external pressures on these countries and introducing coercive changes in the scenarios of their local, regional and international relations. This in turn destabilizes security in the region because it puts external relations on top of the political agenda of the countries of the region. The effect extends to social and cultural levels through unlimited openness to the American model, which affects the future of these societies, their privacy and cultural and social identities.

At the information and media level, several literatures upheld the vision that says that in light of the new elements in the media, the climate of information multilateralism favors more human interaction away from cultural and geographic borders between peoples. However, this generalization implies the idea that the spread democracy has created a foggy image amongst the receivers. This image was exploited by media specialists to hide the effective role that should be played by the media in terms of its relations with the place, and the needs of the individuals and their right to express their positions towards their political and social systems.

\section{Theoretical framework of the study}

The Symbolic Interaction Theory raises the role of language and signs in explaining the communication process in its social framework. Responses are determined through the signs and meanings system, which the individual builds for his life. Therefore, the more the common meaning is, the similar the responses in the social interaction process. This also contributes to increasing the ability of the individual to predict the responses of others towards various positions in the one culture because the individual understands the common meanings in that culture. Hence, we find that the individuals draw pictures of the reality through a certain system of signs and meanings. The individual acquires this system in the communication process. As for the theory of political communication, we have the effect of Marketing Communication, and the Two Step Flow Information Theory, and the Agenda Setting Theory as well as the Soft Power Theory.

When we mention the term political communication, this means that we have to cover three main themes:

1- All forms of communications by officials or political actors in order to achieve certain goals.

2- Communication that is directed to non-politicians such as producers, writers and media professionals.

3- Communication about politicians, and their activities such as writing news reports, information art, talk show of political nature.

\section{There are four levels of analysis of political communications}

1- The effect of the state on the media and the press (licenses, press freedom, taxes, judicial judgments, control over financial support, direct and indirect pressures).

2- The Government information systems. This means the way public information is presented to the public opinion.

3- The impact of the media and the press on the state: The 
relationship between media professionals and the media, the content, and the relationship between information discourse with the political one. In most cases, the media is presented as a subordinate variable not an independent one when speaking about its role in setting the priorities.

4-Role of the political communication in shaping the political culture in the society i.e. its impact in shaping the political behavior and upbringing [1].

Besides this theoretical introduction, the study depends on two other models in support of the complete analysis process. The first theoretical model is common in most critical theories. It presents a vision that thinks that the content of the media organs is to promote for the interests of the hegemonic groups in the society. It is a content that tends to offer imbalanced coverage of the relations. Moreover, the analysis of symbolic meanings of the content, which is used by the stakeholders, reflects the domination (or what is known as content analysis).

The second theoretical model is the global cultural model, which deals with three levels simultaneously, namely: the economic, political, and cultural levels. In this context, the information practice seems like a continuation of hegemony and the making of culture.

\section{Objectives of the Study}

The study aims at analyzing and interpreting the image of the United States in the print Gulf media. It focuses on Al-Khaleej newspaper of the United Arab Emirates and Al-Sharq Al-Awsat newspaper of Saudi Arabia, published in London.

\section{Other sub-objectives include the following}

1- Analyzing the Gulf press coverage of the American model.

2- Analyzing the position of Gulf press towards American decision regarding the issues of the region.

3- The possibility of the Gulf press presenting a conciliatory model combining the agendas of Gulf political regimes and the United States.

Based on the above objectives, this study attempts to answer a number of questions, which would help identify the details of the image of the United States in the Gulf press.

\section{Questions of the study}

1- The main question of this study is to analyze the Image of U.S.A in the Gulf Press?

2- What are the tendencies of the general content of articles and editorials in both newspapers?

3- What are the key subjects and topics that were highlighted in presenting the United States image in the Gulf press?

4- What is the relationship between the agenda of both newspapers and their political reality?

5- What is the intellectual position of writers contracted by both newspapers?

6- What are the points of agreements and differences between both newspapers in dealing with the image of the United States?

\section{The Methodology of the Study}

In this analysis of the published material, the study used the qualitative discourse analysis. In fact the term discourse analysis includes several theories about culture and society. The critical approach has been influenced by the works of Gramsci and Althusser and the school of cultural analysis as well as the works of Fouco and Roland Barth in addition to the French sociologist Pierre Bordeau. The concept was embodied through focusing on the study of the relation of power and hegemony in the society. Many researchers agreed that the practice of power in modern societies no longer depend on coercion in the first place, but on persuasion. This means that it has become an ideological issue. It has also relied on the comparative approach for analyzing the standard and identifying the difference between both newspapers.

Content analysis accords media discourse a different importance. It looks after its privacy with its forms and concepts, in addition to its controversial relation with the society. It not only reflects the reality or power relations and hegemony in the society, but it also contributes to building it through identifying the social identities and shaping discourse as well as selecting the vocabulary. It also investigates contradictions between different discourses and interprets the relation between themselves on the one hand and with the receiving audience on the other. Moreover, discourse plays an effective role in building social relations and identifying social and cultural identities. It is a continuous and complex process in which several variables and local and international forces interact to reflect the positions of the society and its culture as well as the historical stage in which it lives.

On the other hand, recent years have seen great interest in the use of the qualitative approach in humanities studies and research. In the area of information, qualitative approach is used in studying the public (the masses) and the institutions. It is also used in analyzing information texts. Currently, the qualitative text analysis is one of the most important methods in media studies. This method depends on studying the language and conversation and all elements of the text in its cultural context and social significance.

The study selected the Al-Khaleej newspaper of the United Arab Emirates and Al-Sharq Al-Awsat of Saudi Arabia as the sample of the study for the following objective considerations.

1- Al-Khaleej is the one of the oldest daily newspapers in the United Arab Emirates. It has played an important role in shaping the political and national awareness in the Arab region. It has also managed to impose its national agenda in a way that is totally different from what parties that oppose the aspirations of Arab peoples thought. Therefore, it faced a lot of pressures and was forced to close for a specific period after the establishment of the state.

2- Al-Khaleej is one of the Arab newspapers with national if not radical trend in dealing with the main Arab issues.

3- Al-Sharq Al-Awsat is one of the moderate and conservative newspapers in the Arab region.

4- "Al-Khaleej" and "Al-Sharq Al-Awsat" newspapers hire elite of writers, researchers and academics in all human and knowledge sciences.

5- "Al-Khaleej" and "Al-Sharq Al-Awsat" newspapers are amongst the most popular newspapers in the Gulf and the Arab regions.

\section{Categories of the analysis}

Articles and editorials: this is because blogs represent the opinions of writers. An article reflects positions of Arab writers and thinkers 
whatever their ideologies or intellectual affiliations might be. The area of the expression of opinion is adequate for monitoring and analysis through which the researcher can identify and interpret the positions of the newspaper on the issue under discussion.

\section{The time frame of the study}

The researcher selected the period 2007-2008 as the study period, taking into account that this period has seen a lot of events that have raised a lot of controversy about the nature of the interactive relations between the Gulf and the United States.

\section{The sample of the study}

The researcher adopted the method of the regular sample. She selected the first sample on the first day of the first week of 2007. Then she selected the repetition number and its multiplications in selecting the other samples. This sort of samples is the most appropriate in the studies that cover content analysis in the press.

\section{Results of the Study}

\section{First: Results of articles analysis in Al-Khaleej newspaper of UAE}

Articles content analysis in Al-Khaleej newspaper of the United Arab Emirates revealed the following:

- It stressed the fact that the objectives of the US policy in the region are to achieve the American interests and enhance its hegemony on other countries [2].

- It emphasized the fact that the states of Gulf follow the US policy in their strategic plans and policies. The American scenario constitutes a key factor in directing and managing these policies in a way that serves the US interests in the region [3].

- It doubted the ability of the United States to establish a correct reading of the role it can play in the region, with reference to the dilemma it put itself in before the American public opinion because of the occupation of Iraq [4].

- There is a strong ground to support the deterioration of the US reputation in various fields and the failure of the principle of the use of force in subjugating peoples. The study has refuted the American views which often focus on self interest away from the nature of the sound relations that bind the Unites States and some Arab states [5].

- It uncovered American scenarios in the region through hiring Arab writers to cover issues touching the policies of US institutions such as National Intelligence Council in order to explore the future to analyze the future vision of these policies [6].

- It emphasized the need to revive the role of Arab societies and peoples, and gave civil society institutions the right to participate in decision making and strengthen the pillars of democratic practice to face the external model imposed by the United States as an alternative for change inside Arab societies [7].

- It uncovered the brutal practices of the United States through publishing all that is related to the abuses and crimes of the US army in Iraq [8].

- It changed the positive image the United States seeks to establish in the minds of the Arab and international public opinion through responding to the needs of poor and developing peoples [9].
- It cautioned against the issue of internal division, and the danger of civil war as well as the lack of coordination. It also stressed the need for cooperation between the states of the region regarding intervention in Iraq [10].

- It uncovered the serious link between change that may take place as a result of the US presidential elections and the inevitability of a change in the US policy in the region. An analysis of blogs and editorials in the newspaper showed that there are some opinions that call for delinking the two and that the US policy depends more on institutional structure in establishing its strategy than on the change of persons in the American administration [11].

\section{Second: Results of the analysis of blogs in the Saudi newspaper Al-Sbarq Al-Awsat}

Analysis of the content of articles a crnd editorial in Al-Sharq AlAwsat newspaper showed the following:

- It enhanced the idea of dependence through a vision that aims at belittling the value of democracy as a practice and highlighted the serious tests that may take place as if there were a call for change and reformulation of the public opinion concepts towards political participation and activation of the role of civil society organizations. It also defended the idea that all that happened in the Gulf political regimes was an internal change away from any external pressures on Gulf governments from the United States [12].

- It highlighted the gains of the American presence in Iraq and the role it played in the local scene because it has managed to control the situation, which prevented the eruption of a civil war [13].

- It stressed the concerns posed by political regimes in the region (like Iran), which indirectly supports the need for the continuation of the American presence in the region [14].

- It stressed the moral price paid by the United States through its presence in the Gulf region (In Iraq specifically). Some articles mentioned the negative effect of the US policies on the American people, especially the soldiers in the field [15].

- It supported the Gulf public opinion rejection of extremism and terrorism and the call to change concepts amongst the Arab youth to conform to the new international changes as well as the call for cultural and religious rapprochement, especially after the launch by Saudi Arabia of the Dialogue of Religions Initiative [16].

Third: Outcome of comparison between approaches of AlKhaleej and Al-Sharq Al-Awsat newspapers

- The qualitative analysis of articles in Al-Sharq Al-Awsat newspaper showed that there is an absence of any discussion of the reform scenarios proposed by the United States. There is a tendency to fixate the image and attempt to give in to it. The analysis did not show any writings against the American agenda. However it revealed that there is an indirect attempt to accept such an agenda and a call to accept and promote for the American model.

- The analysis of the contents of issues raised in the articles showed that there is an absence of balance in the flow of information. Writers and analysts in both newspapers rely on the foreign source to obtain information about the issues of the region.

- The analysis showed that both newspapers lack the freedom that would enable them to become objective towards the internal issues. 
This made the Gulf press dependent on the inputs of the political regime rather than being an effective player and mover of the public opinion towards national issues.

- The results of the study showed that there is a difference and discrepancy in the position of both newspapers towards political reform in the region. Al-Khaleej newspaper of the United Arab Emirates stressed its rejection of attempts to Americanize the region. It also highlighted, trough the opinion page, the Arab national dimension and the importance that political reforms should come from within the Arab world. Meanwhile, Al-Sharq Al-Awsat newspaper did not show a clear position on this issue.

- The results of the study should that there is a somewhat mixed position between both newspapers in their role in covering the security agreements signed in the Gulf region. The study did not detect any criticism in the blogs of Al-Sharq Al-Awsat newspaper to change the present situation or to uncover the general trends of the US foreign policy in the Middle East. This reflects the fact that the agenda of the newspaper is similar to the US agenda towards the main issues of the region. Meanwhile, the opinion page of Al-Khaleej newspaper presented a critical view against the American scenarios in the region [17].

\section{Conclusion}

Based on the theoretical framework that the study adopted in the qualitative analysis of "the article's subject" in both papers, it seems clear that the Gulf political regimes have a central influence in controlling the editorial policy of the print press, especially in light of the absence of professional independence which is required for the press to express its attitudes towards key issues such as examining the foreign relations of its governments with the international powers like the United States. Especially, this relationship (between Gulf political systems and the United States) has privacy and dimensions related to security and military. In light of media freedoms, this relationship affected on the quality of professional editing, where it was less deep and more limited. The effect of that relationship emerged in Asharq Al-Awsat newspaper more than Al-Alkhaleej. In fact, this weakness in the media coverage and discussion limited reversing the true image of the United States in Gulf Press and probably, in some respects, was contrary to the attitude of people in the Gulf states towards American policies in terms of the region's issues, where they criticize and reject the American domination whether it related to the strategic interests of the Gulf region or the attitude towards the Arab issues, and particularly, its policies towards the Palestinian issue, which is for the Arab peoples is the core national issue.

It seems clear through analysis, in terms of the impact of the relationship between the political ruling system and editorial treatment of the United States' image in the Gulf print media, that there is absence of independent editorial processing, and the media organization is operating under the legislative and legal framework of the political system. This led to the lack of clear policies and specific attitude of the Gulf media to counter the American agenda. Based on that, there is no role for the independent media, it presents the official opinion. In another words, the print media in the Gulf represents the interests of the ruling political system more than the attitudes and trends of the people in the Gulf region.
The results of study revealed that a limited writings dealt with the image of United States, in particular, Asharq Al-Awsat newspaper, but Al-Khaleej was the most "quantitative" and the deepest in "quality" in detection of the true image of the United States of America and clarification of the extent of the depth and limits its strategic role in the region. Finally, the analysis results of the content of both newspapers showed that America's image in the Gulf print media is the image that the political systems want to convey to the public opinion. In response to that, the Gulf newspapers ignore a lot of the relevant issues. Thus, the state's influence in the media is the main determinant of its policies and not vice versa, which means that the state's influence on the media more and more powerful than the impact of the media on the state in viewing and analyzing the image of the United States of America in the print media in the Gulf.

\section{References}

1. Abramson JH (1994) Making Sense of Data. (2ndedn), New York: McCaffee Research

2. AFP: Singapore Says Rules on Use of Internet for Political Discussions Will Remain (2006) World News Connection 05: 31.

3. Analysis: Dutch Critic of Islam Warns Bush (2008) UPI Emerging Threats, 05 19.

4. Bias Against U.S. Muslims on Rise (2008) CBS News.

5. Blethen FA (2004) Stop the Media Mergers. Washington Post, B07.

6. Blogosphere (2008) Information World Review 245: 31

7. Brace P, Hinckley B (1992) Follow the leader: Opinion polls and the modern presidents. New York: Basic Books.

8. Chalk P, Rosenau W (2004) Confronting "The Enemy Within": Security Intelligence, the Police, and Counterterrorism in Four Democracies. Santa Monica, CA: Rand Corporation.

9. Chen C, Wu J, Young SC (2008) Accelerating the Use of Weblogs as an Alternative Method to Deliver Case-Based Learning. International Journal on E-Learning 7: 331-349.

10. Cragin K, Daly SA (2004) The Dynamic Terrorist Threat: An Assessment of Group Motivations and Capabilities in a Changing World. Santa Monica, CA: Rand Corporation.

11. Creswell JW (2009) Research Design: Qualitative, Quantitative, and Mixed Methods Approaches. Thousand Oaks, California: Sage Publications.

12. Iran: Mottaki Says Systematic Effort Launched in West to Insult Islamic Sanctities (2006) World News Connection 6: 19.

13. Jackson PS (1998) Bright star-black sky: A phenomenological study of depression as a window into the psyche of the gifted adolescent. Roeper Review 20: 215-221.

14. Podeschi DM, Wyer RS (1976) Acceptance of Generalizations Based on Inductive and Deductive Evidence. Journal of Personality and Social Psychology 34: 496-509.

15. Witherspoon PD (1991) Within These Walls: A Study of Communication between Presidents and Their Senior Staffs. New York: Praeger Publishers.

16. Al-Jabri MA (1999) Clash of civilizations: The relation of the future? In: Muñoz, G.M. (ed.) Islam, modernism and the West. Cultural and political relations at the end of the millennium. I.B. Tauris Publishers, New York.

17. Berger A (2011) Media and communication research methods: An introduction to Qualitative and Quantitative Approaches. London: Sage Publications. 